\title{
Neutrophil enzymes in urine for the detection of urethral infection in men
}

\author{
P A Fraser, J Teasdale, K S Gan, R Eglin, S C Scott, C J N Lacey
}

\begin{abstract}
Objectives-To determine if assaying the neutrophil enzymes, neutrophil elastase (NE) and myeloperoxidase (MPO) in the urine of men attending a genitourinary medicine clinic could identify those with Neisseria gonorrhoeae or Chlamydia trachomatis infections, and those with urethritis (with or without an identified infection with either organism), and to compare the new assays with the performance of the leucocyte esterase test (LET).

Method-100 men had urethral specimens taken for Gram-stained urethral smear, culture for $\boldsymbol{N}$ gonorrhoeae, and for $C$ trachomatis testing by enzyme immunoassay. First-voided urines were tested for leucocyte esterase by commercial dipstick (positives were defined as greater than "trace") and then frozen at $-20^{\circ} \mathrm{C}$ prior to being assayed for $\mathrm{NE}$ and MPO.
\end{abstract}

Results-Five patients had gonorrhoea, six had chlamydia and none had both. Evidence of urethritis $(>5$ polymorphonuclear leucocytes in four $\times 1000$ fields) was found in 29 men. The results of the urine assays showed MPO levels to be non-discriminatory; however NE levels were significantly elevated in patients with proven infection or urethritis or both. Using NE values from men with no infection or urethritis an upper limit for normal was defined. Utilising this, the sensitivity of the elastase assay was calculated and found to be superior to the sensitivity of LET for detecting proven infection (64\% vs 36\%) and urethritis ( $52 \%$ vs $31 \%)$.

Conclusions-Further studies of neutrophil elastase in the pathogenesis, diagnosis and treatment of urethritis are indicated.

(Genitourin Med 1995;71:176-179)

Keywords: neutrophil elastase; urethritis

Chlamydia trachomatis and Neisseria gonorrhoeae are common sexually transmitted pathogens which may be associated with serious long-term sequelae, particularly in women. ${ }^{1}$ Men with genital infections caused by these organisms often develop urethral discharge or dysuria, but asymptomatic carriage is not uncommon and may represent a reser- voir of infection in the community. Treatment is cheap but diagnosis is expensive and uncomfortable, since it usually involves taking urethral swabs, which many men find unacceptably invasive. The leucocyte esterase test (LET) is a urine dipstick test which detects esterases present in polymorphonuclear leucocytes $^{2}$ (PMNLs) and since men with urethral infection usually have pyuria, LET has been investigated as a cheap, non-invasive screening test for asymptomatic $C$ trachomatis and $N$ gonorrhoeae infections. Initial studies in adolescent males were promising, showing sensitivities for the LET test in detecting urethral infection of $72-100 \% .^{3-5}$ However, subsequent studies in adult males have shown sensitivities of $41-70 \%{ }^{6-8}$ with one of the studies showing the test to be more sensitive in younger men. We decided to extend this strategy by investigating the levels of two other neutrophil enzymes in urine and whether these might be better markers of infection or urethritis. We therefore investigated assays of neutrophil elastase (NE) and myeloperoxidase (MPO), two enzymes which are found in the azurophil granules of PMNLs. MPO reacts with $\mathrm{H}_{2} \mathrm{O}_{2}$ and chloride to produce hypochlorous acid, an oxidant which is thought to be bactericidal, ${ }^{9}$ whilst elastase is a non-specific proteinase, capable of cleaving a wide range of proteins, including human elastin and collagen. NE is a powerful enzyme; its activity is regulated by alpha-1 antitrypsin, a protease inhibitor secreted mainly by the liver. The nature of unregulated neutrophil elastase activity is illustrated by hereditary deficiency of alpha-1 antitrypsin where those affected usually develop pulmonary emphysema. ${ }^{10} \mathrm{NE}$ is also thought to play a significant role in the lung injury which occurs in the adult respiratory distress syndrome. ${ }^{11}$

We investigated urine samples of symptomatic and asymptomatic men attending a genitourinary medicine clinic to determine if those with infections could be identified by the new assays. LET was also performed to compare its sensitivity and specificity.

\section{Materials and methods}

Any male undergoing full genital screening tests in the Department of Genito-urinary Medicine, whether symptomatic or asymptomatic, was considered eligible for the study. One hundred males (age range 18-68 years) were entered into the study. First voided urine samples were collected into sterile containers 
without preservatives or boric acid and were tested for leucocyte esterase with a commercially available dipstick (Multistix 8 SG; Bayer Diagnostics). Results were recorded on a fivepoint colour scale (negative, trace, small, moderate and large) with LET positive urines being defined as those with more than a trace reaction. All urines were then frozen at $-20^{\circ} \mathrm{C}$. Routine sexually transmitted disease (STD) investigations carried out for these patients included Gram staining and microscopy of a urethral smear to document the number of PMNLs and the presence or absence of gonococci, followed by culture on vancomycin-colistin-amphotericin-trimethoprim medium for $N$ gonorrhoeae. A further urethral swab was tested for $C$ trachomatis by EIA (VIDAS-bioMerieux) and blood was taken for syphilis serology.

\section{Urine enzyme assays}

The methods used for determining the urinary levels of NE and MPO were optimised in a series of preliminary experiments which determined assay $\mathrm{pH}$, substrate concentration, assay time and assay volume. For MPO, the optimised assay procedure was as follows. Aliquots $(50 \mu \mathrm{l})$ of buffered urine samples, prepared by mixing urines with an equal volume of $0.5 \mathrm{M}$ phosphate buffer $\mathrm{pH} 5 \cdot 0$, were

Figure 1 Urinary neutrophil elastase activities expressed as arbitrary units $(A U)$.
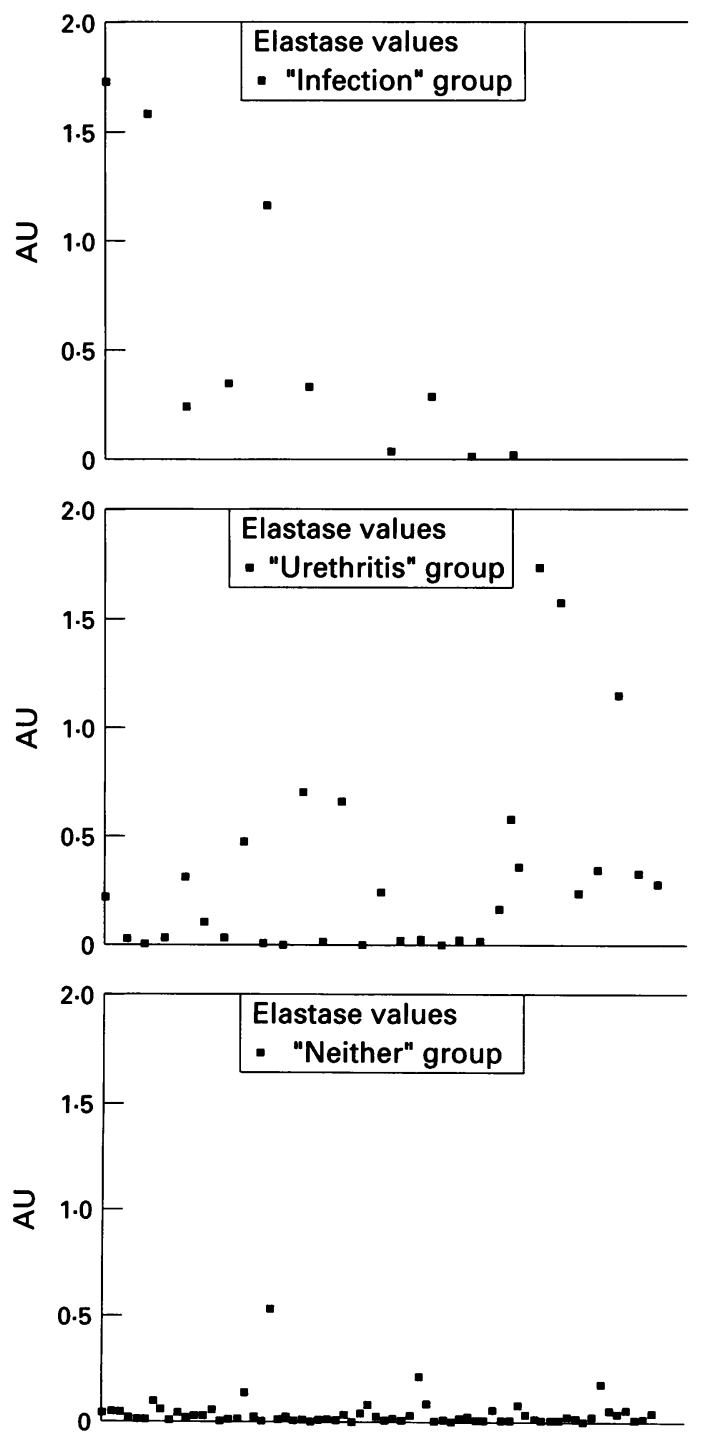

pipetted into microtitre plate wells and prewarmed to $37^{\circ} \mathrm{C}$. O-phenylenediamine substrate solution $(100 \mu \mathrm{l})(4.2 \mathrm{mM}$ substrate dissolved in $50 \mathrm{mM}$ citrate-phosphate buffer pH 5.0 containing $0.3 \mathrm{mM}$ hydrogen peroxide prepared immediately before use) was then added and the absorbance at $492 \mathrm{~nm}$ immediately determined (that is, at time 0 hours) in relation to a substrate blank (that is, $100 \mu \mathrm{l}$ substrate plus $50 \mu \mathrm{l}$ buffer). The reaction mixtures were then incubated at $37^{\circ} \mathrm{C}$ in the dark for three hours after which the $\mathrm{A}_{492}$ values were measured again against the substrate blank (note that the reactions were not stopped with sulphuric acid, as preliminary studies had demonstrated significant colour changes occurring in some urine samples because of an apparent reaction between the acid and the urine pigments). The change in $\mathrm{A}_{492}$ over the three hour period was calculated for each urine and the result expressed as arbitrary units (AU).

For the assay of urinary neutrophil elastase, $50 \mu \mathrm{l}$ of each urine sample was mixed in microtitre plate wells with $100 \mu \mathrm{l}$ of $0 \cdot 1 \mathrm{M}$ Tris- $\mathrm{HCl}$ buffer $\mathrm{pH} 8.3$ containing $0.96 \mathrm{M}$ $\mathrm{NaCl}$ and the microtitre plates then prewarmed to $37^{\circ} \mathrm{C}$. To the buffered urines was then added $50 \mu \mathrm{l}$ of working substrate solution and the absorbance at $405 \mathrm{~nm}$ immediately determined (time 0 ) in relation to a substrate blank (that is, $50 \mu$ l substrate plus $150 \mu \mathrm{l}$ buffer). The plates were then incubated at $37^{\circ} \mathrm{C}$ for three hours in the dark and the $\mathrm{A}_{405}$ measured again against the substrate blank. The change in $A_{405}$ over the three hour period was calculated for each urine and the result expressed as arbitrary units (AU). The L-pyroglutamyl-L-prolyl-L-valine-pnitroanilide (Novabiochem; Switzerland) substrate used in this study is highly specific for neutrophil elastase. ${ }^{12} \mathrm{~A}$ stock $10 \mathrm{mM}$ solution was made by dissolving $25 \mathrm{mg}$ substrate in 5.6 $\mathrm{ml}$ dimethylsulphoxide and this was stored at $4^{\circ} \mathrm{C}$; a working solution was subsequently prepared immediately before use by diluting the stock solution 1:5 with distilled water.

\section{Results}

We first looked at two main outcomes: proven infection, defined as a positive culture for $N$ gonorrhoeae or a positive EIA test for $C$ trachomatis, and evidence of urethritis, defined as $>5$ PMNLs seen in oil immersion microscopy of a Gram-stained urethral smear in four fields at $\times 1000$ magnification. In total, 11 patients had a proven infection, 5 with $N$ gonorrhoeae and 6 with $C$ trachomatis. There were no dual infections. All 5 of those with gonorrhoea, but only 2 of the $C$ trachomatis positive group, had urethritis. In addition, 22 men had urethritis but no defined infection making a total of 29 with urethritis altogether. The remaining 67 men had neither an infection nor urethritis.

\section{Urine enzyme activities}

Analysis of the urines for NE revealed that the majority of urine enzyme activities were below 
Figure 2 Urinary myeloperoxidase activities expressed as arbitrary units $(A U)$.
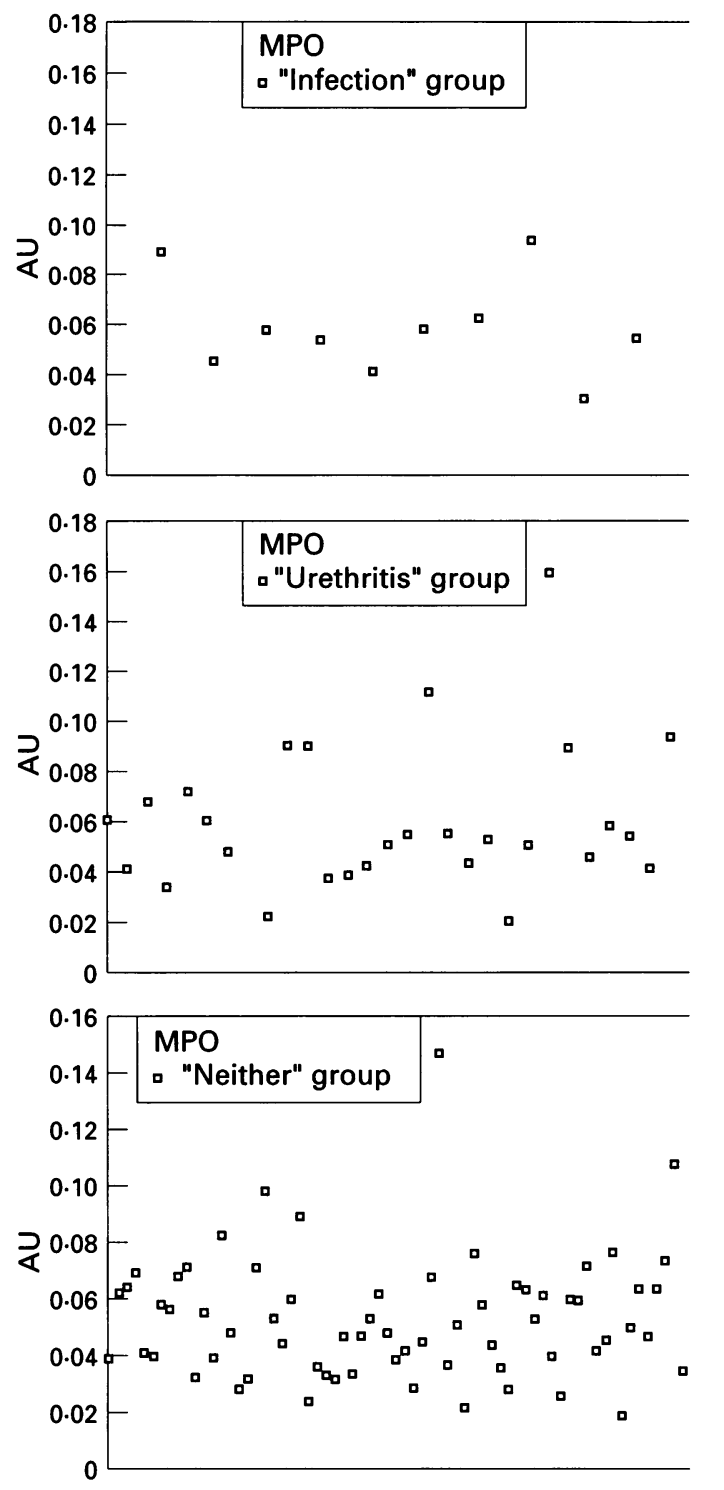

the $0 \cdot 1$ AU level (fig 1). The Mann Whitney test was used to compare the NE urine activities of the men with proven infection with the urine activities of those with no infection or urethritis; NE levels were significantly higher in the infection group $(p=0.003)$. Comparison was also made between the NE activities of the urethritis group and the group with no infection or urethritis; the difference was highly significant $(p<0.001)$

Analysis of the urines for MPO revealed a wide range of activities (fig 2). The Mann Whitney test showed no significant difference between the urine MPO activities of men with infection, men with urethritis and men with neither infection nor urethritis.

\section{Performance of LET}

LET was positive in 10 cases; 4 of 5 of those with gonorrhoea, none of those with $C$ trachomatis infection, 5 of 22 of those with urethritis but no proven infection and 1 of 67 of those with no infection and no urethritis. The sensitivity, specificity, positive predictive and negative predictive values of LET for detecting proven infection were $36 \%, 93 \%, 40 \%$ and $92 \%$ respectively. The corresponding values for detecting urethritis were $31 \%, 98 \%$, $90 \%$ and $78 \%$ (table 1 ).
Table 1 Performance of the leucocyte esterase test

\begin{tabular}{lll}
\hline & Proven infection & Urethritist \\
\hline Sensitivy & $36 \%$ & $31 \%$ \\
Specificity & $93 \%$ & $98 \%$ \\
Positive predictive value & $40 \%$ & $90 \%$ \\
Negative predictive value & $92 \%$ & $78 \%$
\end{tabular}

$\star$ Defined as a positive culture for $N$. gonorrhoeae or a positive ELISA test for $C$. Trachomatis

tDefined as $>5$ PMNLs per $\times 1000$ field seen on oil immersion microscopy of a Gram stained urethral smear.

Table 2 Performance of the elastase assay

\begin{tabular}{lll}
\hline & Proven infection & Urethritis \\
\hline Sensitivity & $64 \%$ & $52 \%$ \\
Specificity & $90 \%$ & $97 \%$ \\
Positive Predictive Value & $44 \%$ & $88 \%$ \\
Negative Predictive Value & $95 \%$ & $83 \%$ \\
\hline
\end{tabular}

Performance of the elastase assay

We took the whole group of elastase values for the patients with neither infection nor urethritis and using ranks calculated the 95 th centile value. This was calculated as $0.195 \mathrm{AU}$ and was defined as the upper limit of the normal range. ${ }^{13}$ We then calculated sensitivity, specificity, positive and negative predictive values for patients with proven infection or urethritis (table 2). The sensitivity of the elastase assay was considerably superior to the LET for detecting proven infection (64 vs $36 \%$ ) and urethritis (52 vs $31 \%$ ).

We then looked at the sub-group of men in the study population who were asymptomatic (that is, they did not complain of urethral discharge or dysuria). In total 72 men were asymptomatic. Of these, 2 were found to have chlamydia infections but no urethritis and 7 had evidence of urethritis but no identified infection. LET was negative in the 2 chlamydia cases but positive in 1 of the 7 urethritis cases and in one additional man who had no infection or urethritis.

The elastase assay was positive in 1 of the chlamydia cases, 2 of the urethritis cases and in an additional 3 men with no infection or urethritis. The sensitivity of LET for detecting urethritis or infection in this subgroup was $11 \%$ compared to $33 \%$ for the NE assay, with specificities, positive predictive values and negative predictive values being very similar for the two tests. However, the small numbers of men with infection/urethritis means that these figures should be interpreted with caution.

We determined whether the elastase values might be correlated with age of the study subjects. Forty four men were $<25$ years and 56 men $>25$ years of age. There was no statistical difference in elastase values between the two groups (Mann Whitney). This was also the case when this analysis was limited to the 29 men with urethritis. Numbers of men with proven infection were too small to make such an analysis valid.

\section{Discussion}

Cheap and simple screening tests for bacterial STDs are urgently needed, particularly in developing countries where STDs can 
increase the risk of acquiring or transmitting HIV three to five fold. ${ }^{14}$ The performance of LET as a screening test in males has been variable, with good results being reported in adolescents, but other authors have described lower sensitivities in adults, ${ }^{6-8}$ as we have found in this study. However, the concept of a urine test for neutrophil enzymes which could be used to screen a population is an appealing one and prompted us to evaluate MPO and $\mathrm{NE}$ as possible candidates.

We have shown in our pilot study that a population of symptomatic and asymptomatic men had a wide range of urinary MPO levels without any discriminative value. In contrast, urinary $\mathrm{NE}$ values were significantly elevated in patients with a proven infection and/or urethritis, compared to those with neither. By using the elastase values of the men without infection or urethritis to define a normal range we have shown that the elastase assay was considerably better than LET in sensitivity. We do, however, accept that these data may be influenced by our use of EIA alone for defining chlamydial infection (which the manufacturers state has an $80 \%$ sensitivity with a $98 \%$ specificity for male urethral specimens). Further studies to more accurately determine the sensitivity of urinary NE assays should ideally incorporate immunofluorescence, cell culture or PCR for Chlamydia trachomatis and PCR for Mycoplasma genitalium. ${ }^{15}$

The divergent behaviour of myeloperoxidase and elastase in their association with urethritis is worthy of further comment. Both enzymes are derived from the primary azurophil granules of neutrophils. Myeloperoxidase though is capable of directly reacting with superoxide and neutralising free radicals generated during the inflammatory response. Consequently MPO levels within urethral secretions might therefore be "selfregulating" and not show disease association. Elastase, however, is clearly capable of inducing endothelial injury, especially in the presence of free radicals or neutrophils which are already activated. ${ }^{11}$ This present study is the first to report significantly increased neutrophil elastase activity in material derived from men with urethritis, and it is tempting to speculate that urinary NE could be directly involved in the pathogenesis. Further studies should be directed towards evaluating its use in the diagnosis of urethritis. One could also postulate that inhibitors of neutrophil chemotaxis ${ }^{16}$ or elastase might have activity in therapy of pathogen-negative chronic urethritis.

We are grateful to Dr M A Waugh, Dr E F Monteiro, and Dr J Wilson for allowing us to study their patients. We also thank Vanessa Dixon for secretarial support.

1 Weström LV, Mårdh PA. Acute pelvic inflammatory disease. In: KK Holmes, P-A Mardh, PF Sparling, PJ Weisner eds, Sexually Transmitted Diseases, 2nd ed. New York, McGraw-Hill, 1990. pp. 593-613.

2 Kusumi KR, Grover PJ, Kunin CM. Rapid detection of pyuria by leucocyte esterase activity. $¥ A M A 1981$; 245: 1653-5.

3 Sadof MD, Woods ER, Emans SJ. Dipstick leucocyte esterase activity in first-catch urine specimens. $\mathscr{f} A M A$ 1987;258:1932-4

4 O'Brien SF, Bell TA, Farrow JA. Use of a leucocyte esterase dipstick to detect Chlamydia trachomatis and Neisseria gonorrhoeae urethritis in asymptomatic adolesNeisseria gonorrhoeae urethritis in asymptomatic adoles-
cent male detainees. Am f Public Health 1988; cent male

5 Shafer MA, Schachter J, Moscicki AB, et al. Urinary leucocyte esterase screening test for asymptomatic chlamydial and gonococcal infections in males. $\mathscr{f} A M A$ 1989; 262:2562-6

6 McNagny SE, Parker MR, Zenilman MJ, Lewis JS. Urinary leucocyte esterase test: a screening method for the detection of asymptomatic chlamydial and gonococcal infections in men. F Infec Dis 1992;165:573-6.

7 White DJ, Malet RM, Bignell CJ. Non-invasive sampling method for detecting Chlamydia trachomatis. Lancet 1989;i:96-7.

8 Patrick DM, Rekart ML, Knowles L. Unsatisfactory performance of the leukocyte esterase test of first voided formance of the leukocyte esterase test of first voided
urine for rapid diagnosis of urethritis. Genitourin Med urine for rapid

9 Smolen JE, Boxer LA. Functions of neutrophils. In: WJ Williams, E Beutler, AJ Erslev, MA Lichtman eds, Haematology, 4th ed, New York, McGraw-Hill, 1992. pp. 780-94.

10 Segal AW, Walport MJ. Neutrophil Leucocytes. In: J O'D McGee, PG Isaacson, NA Wright eds, Oxford Textbook of Pathology, Volume 1. Oxford, Oxford University Press, 1992. pp. 321-9.

11 Repine JE. Scientific perspectives on adult respiratory distress syndrome. Lancet 1992;339:466-9.

12 Kramps JA, Van Twisk CH, Van Der Linden AC. LPyroglutamyl-L-prolyl-L-valine-p-nitroanilide, a highly Pyroglutamyl-L-prolyl-L-valine-p-nitroanilide, a highly specific substrate for granul
Lab Invest 1983;43:427-32.

13 Altman DG. Practical Statistics for Medical Research. London, Chapman and Hall, 1990. pp. 19-47.

14 Berkley S. Diagnostic tests for sexually transmitted diseases: a challenge. Lancet 1994;343:685-6.

5 Horner PJ, Gilroy CB, Thomas BJ, Naidos ROM, TaylorRobinson D. Association of Mycoplasma genitalium with acute non-gonococcal urethritis. Lancet 1993; 342:582-5.

16 Lomas DA, Natin D, Stockley RA, Shahmanesh $M$ Chemotactic activity of urethral secretions in men with urethritis and the effect of treatment. $\mathcal{F}$ Infect Dis 1993;167:233-6. 